\title{
REVIEW
}

\section{Dominantly Inherited Alzheimer Network: facilitating research and clinical trials}

\author{
Krista L Moulder, B Joy Snider, Susan L Mills, Virginia D Buckles, Anna M Santacruz, Randall J Bateman* \\ and John C Morris
}

\begin{abstract}
The Dominantly Inherited Alzheimer Network (DIAN) is an international registry of individuals at risk for developing autosomal dominant Alzheimer's disease (AD). Its primary aims are to investigate the temporal ordering of AD pathophysiological changes that occur in asymptomatic mutation carriers and to identify those markers that herald the transition from cognitive normality to symptomatic AD. DIAN participants undergo longitudinal evaluations, including clinical and cognitive assessments and measurements of molecular and imaging AD biomarkers. This review details the unique attributes of DIAN as a model AD biomarker study and how it provides the infrastructure for innovative research projects, including clinical trials. The recent design and launch of the first anti-amyloid-beta secondary prevention trial in AD, led by the related DIAN Trials Unit, also are discussed.
\end{abstract}

\section{Introduction}

Alzheimer's disease (AD) is the most common form of dementia; an estimated 4.7 million individuals were affected in the US in 2010 [1]. From 2000 to 2010, the age-adjusted death rate from $\mathrm{AD}$ increased by $39 \%$ [2]. Given the accelerated aging of the population as the earliest 'baby boomers' reach age 65, the number of individuals with $\mathrm{AD}$ will increase dramatically and create a public health crisis. Although considerable progress has been made in $\mathrm{AD}$ research over the past decade, much remains to be understood. For example, there still are no disease-modifying therapeutic agents available to alter the course of AD dementia or delay its onset.

Many investigators have suggested that the reason prior trials of potentially disease-modifying drugs have failed in AD thus far is that the drugs were administered too late in the course of the disease [3,4]. AD pathology is present in the brain many years before the onset of clinical symptoms [5-11]. The neuronal and synaptic loss that results in symptomatic AD may preclude clinical benefit when treatment is initiated in symptomatic $A D$, even in its earliest stages. For this reason, many scientists have focused on delineating the mechanisms underlying preclinical $\mathrm{AD}$, wherein the brain pathology of $\mathrm{AD}$ is present but not

\footnotetext{
* Correspondence: batemanr@neuro.wustl.edu; morrisj@abraxas.wustl.edu Department of Neurology, Washington University School of Medicine, 4488 Forest Park Avenue, Suite 130, St. Louis, MO 63108, USA
}

yet sufficient to produce symptoms. Decreases in cerebrospinal fluid (CSF) levels of amyloid-beta 1-42 (A $\left.\beta_{42}\right)$, increases in CSF levels of total tau and phosphorylated tau, and increases in brain amyloid deposition as imaged with Pittsburgh compound B (PIB) in cognitively normal individuals all predict progression to symptomatic AD [12-14]. Key questions that remain, however, are determination of the temporal sequencing of molecular and imaging $\mathrm{AD}$ biomarkers, identifying pathways that should be targeted for therapeutic intervention, and characterizing the ideal window to begin disease-modifying treatment [15].

Defining preclinical AD in individuals who will go on to develop sporadic $\mathrm{AD}$ is complicated by the inability to know precisely whether or when a specific individual will become symptomatic, even in individuals positive for $\mathrm{AD}$ biomarkers such as CSF $\mathrm{A} \beta_{42}$ or brain amyloid imaging. This concern is circumvented, however, in individuals with autosomal dominant $\mathrm{AD}$ (ADAD) because all are destined to develop symptomatic AD. ADAD is caused by a dominant mutation in one of three genes: amyloid precursor protein (APP), presenilin 1 (PSEN1), or presenilin 2 (PSEN2). Although ADAD accounts for less than $1 \%$ of all AD cases [16], its clinical and pathological phenotypes are largely similar to those of sporadic, lateonset AD (LOAD) [17,18]. Children of an affected ADAD parent have a $50 \%$ chance of inheriting the mutated allele. Because ADAD mutations are almost $100 \%$ penetrant, 
mutation carriers are virtually certain to develop symptomatic AD with an age at onset (AAO) very similar to that of their parent $[19,20]$. The more predictable disease course in ADAD will likely facilitate understanding of the prognostic utility and pathogenic implications of biomarkers in asymptomatic mutation carriers.

\section{Value of the Dominantly Inherited Alzheimer Network cohort and assessment protocol}

Because of the rarity of ADAD, research studies have been limited by small sample sizes; therefore, the full scientific value of ADAD families has been difficult to harness. As of July 2013, only 517 ADAD families have been documented worldwide [21]. Moreover, individuals in these families often are geographically dispersed, and so only a handful of mutation carriers may engage in research at a given academic medical center. Molecular biofluid and imaging biomarker ADAD studies report sample sizes in the range of 10 to 60 [22-25]. A national effort to document all ADAD families in France revealed 111 families, but only 42 individuals had CSF biomarker data [26]. The largest known single ADAD kindred, which has approximately 5,000 living relatives and 1,500 PSEN1 E280A mutation carriers, resides in the central northwestern region of Colombia (known as Antioquia) [27]. Two recent reports $[28,29]$ have begun exploration of biomarker changes in this kindred, which had previously been limited by geographic constraints, but again, samples sizes for CSF, magnetic resonance imaging (MRI), and positron emission tomography (PET) imaging were 50 or smaller.

The Dominantly Inherited Alzheimer Network (DIAN) (U19 AG032438; JC Morris, principal investigator [30]) was established in 2008 with the purpose of developing a registry of asymptomatic and symptomatic ADAD mutation carriers and their non-carrier siblings, who serve as a genetically similar control sample. DIAN participants are followed longitudinally by using clinical, cognitive, and imaging and fluid biomarker measures at 14 domestic and international sites (Table 1). Washington University in St Louis, Missouri, serves as the coordinating center for DIAN and as one of the performance sites and thus houses all eight cores: Administration (John C Morris), Clinical (Randall Bateman), Biostatistics (Chengjie Xiong), Neuropathology (Nigel Cairns), Biomarker (Anne Fagan), Genetics (Alison Goate), Imaging (Tammie Benzinger), and Informatics (Daniel Marcus). The target for the DIAN registry is 400 individuals from ADAD families, and 336 have been enrolled as of July 2013. DIAN participants are not required to know their mutation status; asymptomatic enrollees include both mutation carriers and non-carriers in an approximate 50:50 ratio. The percentage of asymptomatic individuals is approximately $75 \%$. Follow-up assessments are scheduled according to the participant's age relative to his or her parental AAO, with assessments every 3 years for asymptomatic individuals until they are within 3 years of the parental AAO, when assessments are done annually; all symptomatic individuals are seen annually. For a more detailed description of the DIAN assessment protocol and infrastructure, please see [31].

The DIAN assessment protocol is designed to be of optimal value for current and future research and ultimately to support clinical trials. First, the large sample size, including a non-carrier control group of individuals from the same families as the mutation carrier individuals, will allow detection of biomarker (or other) changes with a

Table 1 Current Dominantly Inherited Alzheimer's Network sites

\begin{tabular}{lccc}
\hline Site & Location & Site leader & Initiation year \\
\hline Washington University & Randall Bateman & 2008 \\
University of California Los Angeles & St. Louis, MO, USA & John Ringman & 2008 \\
Indiana University & Los Angeles, CA, USA & Bernardino Ghetti & 2008 \\
Columbia University & Indianapolis, IN, USA & Richard Mayeux & Reisa Sperling \\
Brigham \& Women's Hospital & New York, NY, USA & Stephen Salloway & 2008 \\
Butler Hospital & Boston, MA, USA & Martin Rossor & 2008 \\
University College London & Providence, Rl, USA & Colin Masters & 2008 \\
University of Melbourne & London, UK & Ralph Martins & 2008 \\
Edith Cowan University & Melbourne, Australia & Peter Schofield & 2008 \\
University of New South Wales & Perth, Australia & Eric McDade & 2008 \\
University of Pittsburgh & Sydney, Australia & Mathias Jucker & 2008 \\
University of Tubingen & Pittsburgh, PA, USA & Neill Graff-Radford \\
Mayo Clinic, Jacksonville & Tubingen, Germany & Adrian Danek \\
University of Munich & Jacksonville, FL, USA & 2012 \\
\hline
\end{tabular}

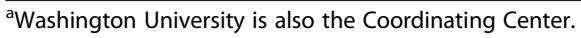


smaller effect size or a shorter duration (or both) than can be seen in smaller samples. Since DIAN is not limited to a single family or mutation type, such analyses have the potential to include scientific questions applicable to all mutation types plus single-mutation and cross-mutation analyses. Second, all DIAN assessments are conducted according to a standard and uniform protocol that allows data from all 14 sites to be readily combined. Standardized measures include the clinical assessment, psychometric testing, non-fasting blood collection for genetics, fasting CSF and blood collection, MRI, amyloid imaging with ${ }^{11} \mathrm{C}$-PIB-PET, and fluorodeoxyglucose-PET (FDG-PET). Tissue collection and storage also are harmonized to allow for biomarker measures within the current scope of DIAN (for example, enzyme-linked immunosorbent assay-based CSF A $\beta$ assays) as well as future methodologies. These data and biospecimens are maintained in a central repository at Washington University to streamline resource sharing; derived data and raw images are stored in the Central Neuroimaging Data Archive in the Informatics Core. Third, the synchronized structure of each DIAN assessment facilitates cross-modality comparisons. For example, imaging variables can be queried against CSF or clinical variables with the confidence that they were all collected within the same 3-month visit window. Fourth, the longitudinal nature of DIAN will provide data to address how $\mathrm{AD}$ biomarkers change over time in a single individual. To date, published reports, including those using initial DIAN data [32], have largely been cross-sectional in nature, with age or relative age used as the reference. Models derived from these cross-sectional analyses of the pathochronology of $\mathrm{AD}$ need to be confirmed with longitudinal data, which DIAN is now collecting. Lastly, DIAN was established with the intent to harmonize as much as possible with protocols used by other multi-center AD studies, including the National Alzheimer's Coordinating Center, the National Cell Repository for Alzheimer's Disease, and the Alzheimer's Disease Neuroimaging Initiative (ADNI). As important as determining the mechanisms and pathways underlying $\mathrm{ADAD}$ is, the ultimate goal is to translate key DIAN findings to the more common, sporadic form of AD. Imaging and biofluid collections and processing protocols are also consistent with the ADNI.

\section{Defining preclinical Alzheimer's disease}

DIAN's design will provide considerable data to characterize preclinical AD more robustly than can occur in sporadic AD. Even with the publication of the National Institute on Aging (NIA)-Alzheimer's Association diagnostic criteria and guidelines for preclinical $\mathrm{AD}$, mild cognitive impairment (MCI) due to AD, and symptomatic AD [33-35], many researchers and clinicians still consider the term preclinical $\mathrm{AD}$ to encompass prodromal $\mathrm{AD}, \mathrm{MCI}$, or very mild AD. The reasoning is twofold: that the very earliest manifestations of AD do not meet the clinical definition of $\mathrm{AD}$ dementia and that individuals with these indications may or may not progress to symptomatic $\mathrm{AD}$. Often, the designation 'conversion to $\mathrm{AD}$ ' is used to delineate the transition from milder forms of dementia (for example, $\mathrm{MCI}$ ) to $\mathrm{AD}$ dementia, implying that the two are distinct entities, not different stages on a continuum of disease. In the DIAN study, preclinical AD refers only to the asymptomatic stage of $\mathrm{AD}$, not to $\mathrm{MCI}$ or prodromal AD. Through the study of ADAD mutation carriers with a virtual $100 \%$ certainty of developing disease, many of the grey areas in sporadic $\mathrm{AD}$ research are removed. An additional benefit is that most DIAN participants are young (the mean parental AAO is $45.7 \pm 6.8$ years [32]) and thus have a low incidence of the comorbidities (for example, vascular disease and diabetes) that can confound AD diagnosis and outcomes in late-onset, sporadic AD. Examining mutation carriers for many years prior to the appearance of symptoms and then in the immediate years after diagnosis allows the earliest cognitive and clinical changes to be documented and verified. Molecular and imaging biomarker data collected throughout can then be viewed with a clear understanding of the participant's clinical status.

Secondary prevention trials for AD will rely heavily on biomarker data to determine when it will be best to begin disease-modifying therapeutics. Considerable evidence shows that biomarker changes can be detected many years before symptom onset [12-15], but the optimal time to begin treatment during this preclinical/asymptomatic phase is much less clear. Normalizing both cross-sectional and longitudinal DIAN data to parental AAO provides an ideal opportunity to rigorously define the temporal ordering of biomarker changes. A well-delineated timecourse of preclinical $\mathrm{AD}$ represents a critical element in the selection of the best therapeutic window. Also, DIAN is structured to provide insight into the predictive power of biomarker values, as single measures or in combination. Various biomarkers - including CSF measurements of $A \beta$ and tau, imaging of amyloid burden, glucose utilization, or brain volumes - and sensitive cognitive testing have been proposed as having predictive power for the development of symptomatic $\mathrm{AD}$, but which single biomarker or combination of biomarkers will be most useful in clinical decision-making remains uncertain. In light of the increasing public health demands of $\mathrm{AD}$, the cost-effectiveness of each of these measures needs to be considered, especially given the recent US Food and Drug Administration (FDA) approval of the ${ }^{18} \mathrm{~F}$ amyloid imaging agent, Amyvid ${ }^{\mathrm{m}}$ (Eli Lilly and Company, Indianapolis, IN, USA) (florbetapir). Although Amyvid ${ }^{\text {Tw }}$ is not currently approved for preclinical imaging, consumer interest, especially by individuals with a family history of $\mathrm{AD}$, is likely to keep this issue in the public debate [36]. 


\section{Rationale for Dominantly Inherited Alzheimer Network Trials Unit clinical trials}

The NIA Request for Applications that led to the establishment of DIAN made specific reference to the notion that DIAN participants would represent an attractive cohort in which to evaluate potential therapies for AD, although funding for such trials was not included in the DIAN observational study. In addition to the reasons mentioned earlier, including a virtual certainty of the development of disease in mutation carriers and a predictable AAO, the DIAN cohort is a logical focus of pharmaceutical companies because almost all disease-modifying therapies currently being tested have been developed by using cell culture and animal models based on ADAD mutations. All ADAD mutations in APP, PSEN1, and PSEN2 result in an increase in the production of $A \beta$ species or in the $A \beta_{42 / 40}$ ratio $[37,38]$, providing very strong support for the amyloid hypothesis in AD. ADAD mutations have been introduced into several mouse models, which served as the initial screen for existing anti-A $\beta$ antibody therapies, beta-secretase inhibitors, and gamma-secretase inhibitors. The recent failures of a few of these proposed diseasemodifying drugs in phase II or phase III trials could be due to limitations of translating animal results into human disease, or the drugs may have been administered too late in the disease course, as all trials enrolled individuals who already had symptomatic AD [39]. Testing these agents in cognitively normal ADAD mutation carriers (that is, preclinical $\mathrm{AD}$ ) may represent the best possibility for measurable benefit in either biomarker outcomes or prevention of cognitive decline.

In 2009, the Clinical Core Leader for DIAN, Randall Bateman, formed the Clinical Trials Committee (CTC) to oversee the design of therapeutic trials in the DIAN cohort. The CTC was composed of DIAN Steering Committee members, clinical trial experts, regulatory advisors, and ADAD family member representatives. CTC aims were to evaluate potential trial designs and to determine which therapeutic targets are likely to be most amenable to treatment. The CTC was then transitioned to the DIAN Trials Unit (DIAN-TU), and funds were provided by the Alzheimer's Association and the DIAN Pharma Consortium. The DIAN-TU is led by Bateman to coordinate, manage, and implement DIAN trials and interface with the DIAN longitudinal study to coordinate study goals and the interests of DIAN participants.

The DIAN Pharma Consortium [40] was created by the DIAN-TU and 10 collaborating pharmaceutical companies to provide the funds, expertise, expanded registry [41], and drug nomination support necessary to develop the infrastructure for DIAN trials. Beginning in 2010, the DIAN CTC, and later the DIAN-TU, requested therapy nominations from pharmaceutical companies; 15 compounds from 13 companies were submitted. The DIAN
Therapy Evaluation Committee - led by Bateman with the supervision of Maria Carrillo, of the Alzheimer's Association, as conflict-of-interest manager - was formed with members of the DIAN Steering Committee and external consultants to evaluate each nomination independently and determine potential suitability for trial inclusion on the basis of preclinical and clinical data.

The DIAN-TU design leverages the existing infrastructure of the ongoing DIAN longitudinal study and builds upon important DIAN baseline and rate-of-change data. The trial was designed as a randomized, blinded, placebocontrolled four-arm trial with a target of 160 asymptomatic to mildly symptomatic mutation carrier participants who are -15 to +10 years of their estimated AAO ( 40 per arm; Figure 1). Participants will receive either drug or placebo for 2 years to determine engagement of the central nervous system target and effects of treatment on downstream biomarkers and to collect safety data. Each drug arm will be compared with the pooled placebo group. By diversifying the drug portfolio at the outset of the trial, investigators minimize the risk of having a failed agent in this highly informative and rare population. The pooled placebo group greatly increases efficiency, allowing for a trial of 160 mutation carriers that, if conducted separately, would require 240 mutation carriers. The pooled placebo group also increases the participant's likelihood of receiving active drug (75\%) compared with traditional designs (50\%), an issue that current DIAN participants have identified as being particularly important. The trial will include mildly symptomatic individuals because this group will also be informative of anti-A $\beta$ drug effects on biomarkers. Enrollment of symptomatic individuals will be limited to less than $50 \%$ and will be evenly distributed across arms by using a minimization strategy. Since many DIAN participants are unaware of their mutation status, both mutation carriers and non-carriers will be enrolled and participants and study staff will remain naïve to mutation status. Mutation non-carriers will be assigned to placebo (planned enrollment of not more than 80 non-carriers), and total trial enrollment will be 240 individuals. Noncarriers will undergo all testing and will provide important biomarker data in a young healthy cohort.

The first two drugs selected for the DIAN-TU trial are listed in Table 2. Plans to launch a third arm, using the beta-secretase inhibitor LY2886721, were put on hold with the recent announcement of adverse events. The trial design allows for ongoing consideration of other drugs for possible addition to the trial.

Since each drug selected has a different mechanism of action and there is not an identified AD surrogate biomarker universally accepted as the 'gold standard', a panel of $\mathrm{AD}$ biomarkers is included to determine which therapeutic agent best impacts different aspects of $\mathrm{AD}$ pathology: volumetric MRI, functional connectivity MRI, 


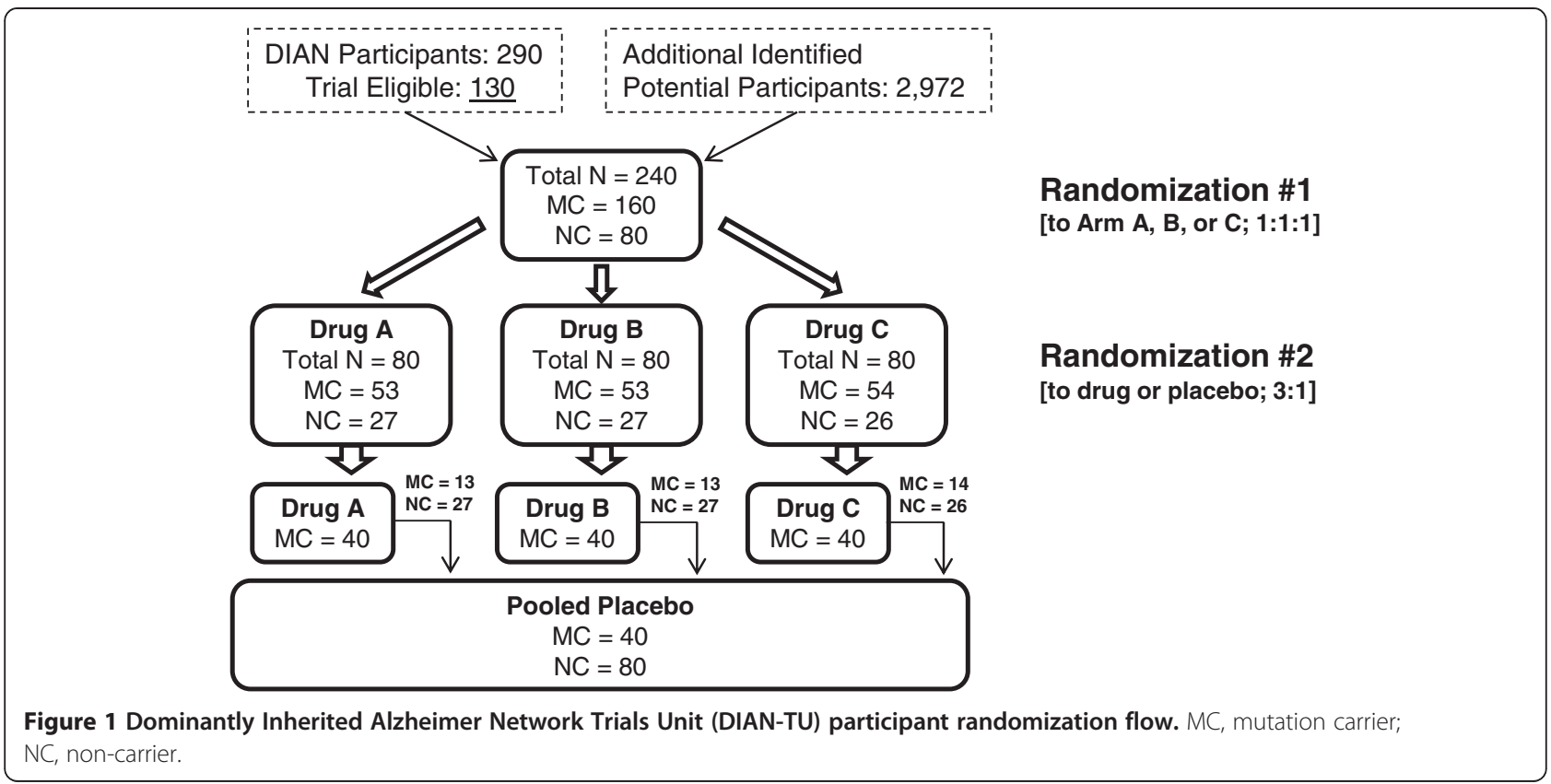

FDG-PET, PET amyloid imaging, CSF A $\beta$, CSF tau, and CSF phospho-tau. It is unlikely that a drug that does not hit its target mechanism of action will be effective in preventing or slowing cognitive decline. Cognitive measures are also included to serve as baseline measures for a potential seamless extension to a subsequent phase III cognitive endpoint trial and to demonstrate the sensitivity of cognitive measures in individuals with very mild or no clinically apparent cognitive impairment.

The DIAN-TU trial received FDA approval in late 2012 and was officially launched on 31 December 2012 with enrollment of the first trial participant at Washington University. As of July 2013, five participants have been randomly assigned to a treatment arm at Washington University and have received the first dose of active agent or placebo. Other DIAN-TU sites are in the process of being activated. With these steps, the first secondary prevention trial with putative 'disease-modifying' drugs in the field of $\mathrm{AD}$ has begun. In collaboration with the planned Alzheimer's Prevention Initiative (API) and Anti-Amyloid Treatment in Asymptomatic AD (A4) trials $[42,43]$, the DIAN-TU trial provides an opportunity to test fundamental ideas about preclinical $\mathrm{AD}$ and $\mathrm{AD}$ progression. Together, these efforts should dovetail to accelerate therapeutic development for both ADAD and sporadic AD.

\section{Conclusions}

Unless therapies that slow or prevent AD are developed, the global increase in longevity and resulting increase in people with $\mathrm{AD}$ will have a devastating impact on many more millions of individuals and their families and on the finances and resources of health-care systems and societies. A key question in therapeutic development is when treatments will be most effective in the course of $\mathrm{AD}$. Even in cognitively normal older adults with biomarker evidence of preclinical AD (for example, low CSF A $\beta$ ), it is unclear when the pathology will manifest itself as symptomatic LOAD. Study of ADAD families has the potential to shape the answer to this question because mutation carriers typically develop clinical disease at about the same age as their affected parent. Therefore, biomarker measurements made during the preclinical stage of disease in these individuals can be ordered relative to the parental AAO, resulting in a better understanding of the therapeutic window for prevention or attenuation of disease.

Table 2 First two therapeutic agents in the Dominantly Inherited Alzheimer Network trials unit

\begin{tabular}{|c|c|c|c|c|}
\hline Drug & Type & Mechanism of action biomarker & Downstream biomarkers & Exploratory biomarkers \\
\hline $\begin{array}{l}\text { Solanezumab } \\
\text { (Eli Lilly and Company) }\end{array}$ & $\begin{array}{l}\text { Anti-A } \beta \text { antibody } \\
\text { (soluble } A \beta \text { ) }\end{array}$ & CSF total and free $A \beta_{40}$ and $A \beta_{42}$ & CSF tau, ptau181, vMRI & FDG-PET, fCMRI \\
\hline Gantenerumab (Roche) & $\begin{array}{l}\text { Anti-A } \beta \text { antibody } \\
\text { (aggregated } A \beta \text { ) }\end{array}$ & PET amyloid imaging & CSF tau, ptau181, vMRI & FDG-PET, fCMRI \\
\hline
\end{tabular}

$\mathrm{A} \beta$, amyloid-beta; CSF, cerebrospinal fluid; fcMRl, functional connectivity magnetic resonance imaging; FDG-PET, fluorodeoxyglucose-positron emission tomography; PET, positron emission tomography; vMRI, volumetric magnetic resonance imaging. 
DIAN is a unique research effort that has collected the world's largest cohort of ADAD individuals from multiple families and mutation types. The longitudinal comprehensive assessment of DIAN participants, including clinical, cognitive, and biomarker measures, is designed to facilitate future research and clinical trials. Indeed, DIAN-TU has already launched the first such trial. The DIAN-TU trial and the planned API and A4 secondary prevention trials have hopefully positioned the field of $\mathrm{AD}$ research at the cusp of developing truly effective drugs available for those at risk for either autosomal dominant or sporadic AD.

Note: This article is part of a series on Tau-based therapeutic strategies, edited by Leonard Petrucelli. Other articles in this series can be found at http://alzres.com/series/tau_therapeutics

\section{Abbreviations}

A4: Anti-Amyloid Treatment in Asymptomatic Alzheimer's Disease; AB: Amyloid-beta; AAO: Age at onset; AD: Alzheimer's disease; ADAD: Autosomal dominant Alzheimer's disease; ADNI: Alzheimer's Disease Neuroimaging Initiative; API: Alzheimer's Prevention Initiative; APP: Amyloid precursor protein; CSF: Cerebrospinal fluid; CTC: Clinical Trials Committee; DIAN: Dominantly Inherited Alzheimer Network; DIAN-TU: Dominantly Inherited Alzheimer Network Trials Unit; FDA: US Food and Drug Administration; FDG-PET: Fluorodeoxyglucose-positron emission tomography; LOAD: Late-onset Alzheimer's disease; MCl: Mild cognitive impairment; MRI: Magnetic resonance imaging; NIA: National Institute on Aging; PET: Positron emission tomography; PIB: Pittsburgh compound B; PSEN: Presenilin.

\section{Competing interests}

RJB has financial affiliations with the following entities: AstraZeneca (London, UK), Biogen Idec (Weston, MA, USA), C2N Diagnostics (St. Louis, MO, USA), Eisai (Woodcliff Lake, NJ, USA), Elan (Dublin, Ireland), Eli Lilly and Company, EnVivo (Watertown, MA, USA), Genentech (South San Francisco, CA, USA), Hoffmann-La Roche (Grenzach-Wyhlen, Germany), Janssen (Neuss, Germany), Medtronic (Minneapolis, MN, USA), Merck \& Co. (Whitehouse Station, NJ, USA), Mithridion, Inc. (Madison, WI, USA), Novartis (Basel, Switzerland), Pfizer Inc. (New York, NY, USA), and Sanofi (Paris, France). JCM has financial affiliations with the following entities: Eisai, Esteve (Barcelona, Spain), GlaxoSmithKline (Uxbridge, Middlesex, UK), Janssen, Novartis, Otsuka (Tokyo, Japan), and Pfizer Inc. The DIAN Pharma Consortium (which supports the DIAN-TU but not the DIAN observational study) consists of Biogen Idec, Elan, Genentech, Janssen, Eli Lilly and Company, Mithridion, Novartis, Pfizer Inc., Roche (Basel, Switzerland), and Sanofi. The other authors declare that they have no competing interests.

\section{Acknowledgments}

The authors thank the DIAN participants and their families for their time, altruism, and dedication, and the faculty and staff at each of the DIAN sites for their contributions to the study. The present work was supported by U19 AG032438 (JCM, principal investigator), the DIAN-TU, the Alzheimer's Association, the DIAN Pharma Consortium, the generous support of Fred Simmons and Olga Mohan, the German Center for Neurodegenerative Diseases (DZNE), and a grant from an anonymous foundation.

\section{Published: 17 Oct 2013}

\section{References}

1. Hebert LE, Weuve J, Scherr PA, Evans DA: Alzheimer disease in the United States (2010-2050) estimated using the 2010 census. Neurology 2013, 80:1778-1783.

2. Tejada-Vera B: Mortality From Alzheimer's Disease in the United States: Data for 2000 and 2010. NCHS data brief, no. 116. National Center for Health Statistics: Hyattsville, MD; 2013.
3. Holtzman DM, Morris JC, Goate AM: Alzheimer's disease: the challenge of the second century. Sci Transl Med 2011, 77:77sr1.

4. Sperling RA, Jack CR, Aisen PS: Testing the right target and right drug at the right stage. Sci Transl Med 2011, 3:111cm33.

5. Price JL, McKeel DW, Buckles VD, Roe CM, Xiong C, Grundman M, Hansen LA, Petersen RC, Parisi JE, Dickson DW, Smith CD, Davis DG, Schmitt FA, Markesbery WR, Kaye J, Kurlan R, Hulette C, Kurland BF, Higdon R, Kukull W, Morris JC: Neuropathology of nondemented aging: presumptive evidence for preclinical Alzheimer disease. Neurobiol Aging 2009, 30:1026-1036.

6. Price $J$, Morris JC: Tangles and plaques in nondemented aging and 'preclinical' Alzheimer's disease. Annals Neurol 1999, 45:358-368.

7. Knopman DS, Parisi JE, Salviati A, Floriach-Robert M, Boeve BF, Ivnik RJ, Smith GE, Dickson DW, Johnson KA, Petersen LE, McDonald WC, Braak H, Petersen RC: Neuropathology of cognitively normal elderly. J Neuropathol Exp Neurol 2003, 62:1087-1095.

8. Bennett DA, Schneider JA, Arvanitakis Z, Kelly JF, Aggarwal NT, Shah RC, Wilson RS: Neuropathology of older persons without cognitive impairment from two community-based studies. Neurology 2006, 66:1837-1844.

9. Price JL, Ko Al, Wade MJ, Tsou SK, McKeel DW Jr, Morris JC: Neuron number in the entorhinal cortex and CA1 in preclinical Alzheimer disease. Arch Neurol 2001, 58:1395-1402.

10. Gomez-Isla T, Price JL, McKeel DW, Morris JC, Growdon JH, Hyman BT: Profound loss of layer II entorhinal cortex neurons occurs in very mild Alzheimer's disease. J Neurosci 1996, 16:4491-4500.

11. Monsell SE, Mock C, Roe CM, Ghoshal N, Morris JC, Cairns NJ, Kukull W: Comparison of symptomatic and asymptomatic persons with Alzheimer disease neuropathology. Neurology 2013, 80:2121-2129.

12. Fagan AM, Roe CM, Xiong C, Morris JC, Holtzman DM: Cerebrospinal fluid tau/ $\beta$-amyloid 42 ratio as a prediction of cognitive decline in nondemented older adults. Arch Neurol 2007, 64:343-349.

13. Morris JC, Roe CM, Grant EA, Head D, Storandt M, Goate AM, Fagan AM, Holtzman DM, Mintun MA: Pittsburgh Compound B imaging and prediction of progression from cognitive normality to symptomatic Alzheimer's disease. Arch Neurol 2009, 66:1469-1475.

14. Villemagne VL, Pike KE, Chetelat G, Ellis KA, Mulligan RS, Bourgeat P, Ackermann U, Jones G, Szoeke C, Salvado O, Martins R, O'Keefe G, Mathis CA Klunk WE, Ames D, Masters CL, Rowe CC: Longitudinal assessment of $A \beta$ and cognition in aging and Alzheimer disease. Annals Neurol 2011, 69:181-192.

15. Jack CR, Knopman DS, Jagust WJ, Petersen RC, Weiner MW, Aisen PS, Shaw LM, Vemuri P, Wiste HJ, Weigand SD, Lesnick TG, Pankratz VS, Donohue MC, Trojanowski JQ: Tracking pathophysiological processes in Alzheimer's disease: an updated hypothetical model of dynamic biomarkers. Lancet Neurol 2013, 12:207-216.

16. Nussbaum RL, Ellis CE: Alzheimer's disease and Parkinson's disease. N Engl $J$ Med 2003, 348:1356-1364.

17. Snider BJ, Norton J, Coats MA, Chakraverty S, Hou CE, Jervis R, Lendon CL, Goate AM, McKeel DW, Morris JC: Novel Presenilin 1 mutation (S170F) causing Alzheimer disease with Lewy bodies in the third decade of life. Arch Neurol 2005, 62:1821-1830.

18. Bateman RJ, Aisen PS, Strooper BD, Fox NC, Lemere CA, Ringman JM, Salloway S, Sperling RA, Windisch M, Xiong C: Autosomal-dominant Alzheimer's disease: a review and proposal for the prevention of Alzheimer's disease. Alzheimers Res Ther 2011, 3:1.

19. Lippa CF, Swearer JM, Kane KJ, Nochlin D, Bird TD, Ghetti B, Nee LE, St George-Hyslop P, Pollen DA, Drachman DA: Familial Alzheimer's disease: site of mutation influences clinical phenotype. Annals Neurol 2000, 48:376-379.

20. Mullan M, Houlden H, Crawford F, Kennedy A, Rogues P, Rossor M: Age of onset in familial early onset Alzheimer's disease correlates with genetic aetiology. Am J Med Genet Neuropsychiat Genet 1993, 48:129-130.

21. Cruts M, Theuns J, Van Broeckhoven C: Locus-specific mutation databases for neurodegenerative brain diseases. Hum Mutat 2012, 33:1340-1344.

22. Fox NC, Warrington EK, Seiffer AL, Agnew SK, Rossor MN: Presymptomatic cognitive deficits in individuals at risk of familial Alzheimer's disease: a longitudinal prospective study. Brain 1998, 121:1631-1639.

23. Mosconi L, Sorbi S, de Leon MJ, Nacmias B, Myoung PS, Tsui W, Ginestroni A, Bessi V, Fayyazz M, Caffarra P, Pupi A: Hypometabolism exceeds atrophy in presymptomatic early-onset familial Alzheimer's disease. J Nucl Med 2006, 47:1778-1786.

24. Ringman JM: What the study of persons at risk for familial Alzheimer's disease can tell us about the earliest stages of the disorder: a review. J Geriatr Psychiatry Neurol 2005, 18:228-233. 
25. Knight WD, Kim LG, Douiri A, Frost C, Rossor MN, Fox NC: Acceleration of cortical thinning in familial Alzheimer's disease. Neurobiol Aging 2011, 32:1765-1773.

26. Wallon D, Rousseau S, Rovelet-Lecrux A, Quillard-Muraine M, Guyant-Mar échal L, Martinaud O, Pariente J, Puel M, Rollin-Sillaire A, Pasquier F, Le Ber I, Sarazin $\mathrm{M}$, Croisile B, Boutoleau-Bretonnière $C$, Thomas-Antérion C, Paquet C, Moreaud O, Gabelle A, Sellal F, Sauvée M, Laquerrière A, Duyckaerts C, Delisle MB, Streichenberger N, Lannes B, Frebourg T, Hannequin D, Campion D: The French series of autosomal dominant early onset Alzheimer's disease cases: mutation spectrum and cerebrospinal fluid biomarkers. J Alzheimers Dis 2012, 30:847-856.

27. Lopera F, Ardilla A, Martinez A, Madrigal L, Arango-Viana JC, Lemere CA, Arango-Lasprilla JC, Hincapíe L, Arcos-Burgos M, Ossa JE, Behrens IM, Norton J, Lendon C, Goate AM, Ruiz-Linares A, Rosselli M, Kosik KS: Clinical features of early-onset Alzheimer disease in a large kindred with an E280A presenilin-1 mutation. JAMA 1997, 277:793-799.

28. Fleisher AS, Chen K, Quiroz YT, Jakimovich LJ, Gomez MG, Langois CM, Langbaum JB, Ayutyanont N, Roontiva A, Thiyyagura P, Lee W, Mo H, Lopez L, Moreno S, Acosta-Baena N, Giraldo M, Garcia G, Reiman RA, Huentelman MJ, Kosik KS, Tariot PN, Lopera F, Reiman EM: Florbetapir PET analysis of amyloid- $\beta$ deposition in the presenilin 1 E280A autosomal dominant Alzheimer's disease kindred: a cross-sectional study. Lancet Neurol 2012, 11:1057-1065.

29. Reiman EM, Quiroz YT, Fleisher AS, Chen K, Velez-Pardo C, Jimenez-Del-Rio M, Fagan AM, Shah AR, Alvarez S, Arbelaez A, Giraldo M, Acosta-Baena N, Sperling RA, Dickerson B, Stern CE, Tirado V, Munoz C, Reiman RA, Huentelman MJ, Alexander GE, Langbaum JB, Kosik KS, Tariot PN, Lopera F: Brain imaging and fluid biomarker analysis in young adults at genetic risk for autosomal dominant Alzheimer's disease in the presenilin 1 E280A kindred: a case-control study. Lancet Neurol 2012, 11:1048-1056.

30. Dominantly Inherited Alzheimer Network home page. http://dian-info.org/.

31. Morris JC, Aisen PS, Bateman RJ, Benzinger TL, Cairns NJ, Fagan AM, Ghetti B, Goate AM, Holtzman DM, Klunk WE, McDade E, Marcus DS, Martins RN, Masters CL, Mayeux R, Oliver A, Quaid K, Ringman JM, Rossor MN, Salloway S, Schofield PR, Selsor NJ, Sperling RA, Weiner MW, Xiong C, Moulder KL, Buckles VD: Developing an international network for Alzheimer research: The Dominantly Inherited Alzheimer Network. Clin Invest 2012, 2:975-984.

32. Bateman RJ, Xiong C, Benzinger TL, Fagan AM, Goate A, Fox NC, Marcus DS, Cairns NJ, Xie X, Blazey TM, Holtzman DM, Santacruz A, Buckles V, Oliver A, Moulder K, Aisen PS, Ghetti B, Klunk WE, McDade E, Martins RN, Masters CL, Mayeux R, Ringman JM, Rossor MN, Schofield PR, Sperling RA, Salloway S, Morris JC: Clinical and biomarker changes in dominantly inherited Alzheimer's disease. N Engl J Med 2012, 367:795-804.

33. Sperling RA, Aisen PS, Beckett LA, Bennett DA, Craft S, Fagan AM, Iwatsubo T, Jack CR Jr, Kaye J, Montine TJ, Park DC, Reiman EM, Rowe CC, Siemers E, Stern Y, Yaffe K, Carrillo MC, Thies B, Morrison-Bogorad M, Wagster MV Phelps $\mathrm{CH}$ : Toward defining the preclinical stages of Alzheimer's disease: recommendations from the National Institute on Aging-Alzheimer's Association workgroups on diagnostic guidelines for Alzheimer's disease. Alz Dement 2011, 7:280-292.

34. Albert MS, DeKosky ST, Dickson D, Dubois B, Feldman HH, Fox NC, Gamst A, Holtzman DM, Jagust WJ, Petersen RC, Snyder PJ, Carrillo MC, Thies B, Phelps $\mathrm{CH}$ : The diagnosis of mild cognitive impairment due to Alzheimer disease: recommendations from the National Institute on AgingAlzheimer's Association workgroups on diagnostic guidelines for Alzheimer's disease. Alz Dement 2011, 7:270-279.

35. McKhann GM, Knopman DS, Chertkow H, Hynes M, Jack CR, Kawas CH, Klunk WE, Koroshetz WJ, Manly JJ, Mayeux R, Mohs RC, Morris JC, Rossor MN, Scheltens P, Carrillo MC, Thies B, Weintraub S, Phelps CH: The diagnosis of dementia due to Alzheimer's disease: recommendations from the National Institute on Aging and the Alzheimer's Association workgroup. Alz Dement 2011, 7:263-269.

36. Snider BJ, Buckles VD: 'Will I get Alzheimer disease?' when cognitively normal patients ask to be tested for Alzheimer disease. Continuum 2013 19:470-474.

37. Scheuner D, Eckman C, Jensen M, Song X, Citron M, Suzuki N, Bird TD, Hardy J, Hutton M, Kukull W, Larson E, Levy-Lahad E, Viitanen M, Peskind E, Poorkaj P, Schellenberg G, Tanzi R, Wasco W, Lannfelt L, Selkoe D, Younkin S: Secreted amyloid beta-protein similar to that in the senile plaques of Alzheimer's disease is increased in vivo by the presenilin 1 and 2 and APP mutations linked to familial Alzheimer's disease. Nat Med 1996, 2:864-870.
38. Kuperstein I, Broersen K, Benilova I, Rozenski J, Jonckheere W, Debulpaep M, Vandersteen A, Segers-Nolten I, Van Der Werf K, Subramaniam V, Braeken D, Callewaert G, Bartic C, D'Hooge R, Martins IC, Rousseau F, Schymkowitz J, De Strooper B: Neurotoxicity of Alzheimer's disease $A \beta$ peptides is induced by small changes in the $A \beta 42$ to $A \beta 40$ ratio. EMBO 2010, 29:3408-3420.

39. Bateman RJ, Klunk WE: Measuring target effect of proposed disease-modifying therapies in Alzheimer's disease. Neurotherapeutics 2008, 5:381-390.

40. Dominantly Inherited Alzheimer's Network (DIAN) Expanded Registry Pharma Consortium Members. http://dianxr.org/pharma.htm.

41. Dominantly Inherited Alzheimer's Network (DIAN) Expanded Registry. http:// www.dianxr.org/.

42. Carrillo MC, Brashear HR, Logovinsky V, Ryan JM, Feldman HH, Siemers ER, Abushakra S, Hartley DM, Petersen RC, Khachaturian AS, Sperling RA: Can we prevent Alzheimer's disease? Secondary 'prevention' trials in Alzheimer's disease. Alz Dement 2013, 9:123-131.

43. Reiman EM, Langbaum JB, Fleisher AS, Caselli RJ, Chen K, Ayutyanont N, Quiroz YT, Kosik KS, Lopera F, Tariot PN: Alzheimer's Prevention Initiative: a plan to accelerate the evaluation of presymptomatic treatments. J Alz Dis 2011, 26S3:321-329.

\subsection{6/alzrt213}

Cite this article as: Moulder et al:: Dominantly Inherited Alzheimer Network: facilitating research and clinical trials. Alzheimer's Research \& Therapy 2013, 5:48 